\title{
ESTUDO PARA O AUMENTO DO DESEMPENHO DOS CILINDROS DE TRABALHO DO LAMINADOR DE TIRAS A FRIO DA CSN/UPV*
}

\section{Resumo}

Gilson Teixeira Cornélio 1 Guaraci da Silva Baylão Felipe Siqueira de Moraes $^{2}$ Mario Vitor Leite ${ }^{1}$

O presente trabalho tem como objetivo aumentar o desempenho dos cilindros de trabalho utilizados para laminação de tiras a frio. A motivação deste é a busca por competitividade do processo de laminação por meio da redução de seus custos e que neste caso será focado no consumo de cilindros, ferramenta que afeta diretamente no custo final do produto laminado. Para atender a esse objetivo foram conduzidas três atividades no laminador de tiras a frio da CSN, dedicado a produção de material para indústria automobilística, as quais foram: i) investigação detalhada do comportamento do cilindro durante sua aplicação o que consiste em identificar as principais causas de consumo dos cilindros que prejudicam seu desempenho. ii) desenvolver o processo de fabricação dos cilindros Villares Rolls para que possam oferecer as propriedades mecânicas adequadas para as causas de consumo. iii) fabricar cilindros para teste e avaliar seu desempenho no laminador, investigando-os para identificar pontos de melhoria. Os resultados indicam que as mudanças propostas e realizadas nos cilindros atendem às solicitações durante sua utilização no laminador uma vez que seu desempenho tem sido $22 \%$ superior quando comparado àquelas praticadas atualmente.

Palavras-chave: Laminador de tiras a frio; Consumo de cilindros; Cilindros forjados.

\section{DEVELOPMENTS IN THE ROLLING MILL ROLLS FOCUSED ON THE CSN/UPV COLD STRIP MILL}

\begin{abstract}
In the present days, the steel industry is aiming for competitivity and because of this its processes are being looked at closely in order to identify possibilities to increase productivity and reduce the costs of production. The consumption of rolling mill rolls is an important variable related to the costs of production, i.e, an increase on their performance could reduce the costs of production. In this paper, the reasons for roll consumption in the CSN cold strip mill, which is dedicated to the automobile industry, were investigated and those results were used to support developments in the Villares Rolls applied in the CSN cold strip mill. The results with prototypes show a significant reduction in the consumption of the roll, which has increased the quantity of rolled material per millimeter of roll consumption compared to the actual specification of the rolling mill roll.
\end{abstract}

Keywords: Cold strip mill; Roll consumption; Forged roll.

1 Representação comercial dos cilindros Villares Rolls, Pindamonhangaba, SP, Brasil.

2 CSN, Volta Redonda, RJ, Brasil.

* Contribuição técnica ao $51^{\circ}$ Seminário de Laminação - Processos e Produtos Laminados e Revestidos, 28 a 31 de outubro de 2014, Foz do Iguaçu, PR, Brasil. 


\section{INTRODUÇÃO}

Os cilindros da marca Villares Rolls de aço forjado com teores de cromo de $3 \%$ e $5 \%$ são amplamente utilizados nos laminadores de tiras a frio por mais de 50 anos. Embora tenham sido desenvolvidas novas ligas como, por exemplo, o aço rápido forjado, os cilindros de aço forjado ligado ao cromo, sejam da marca Villares Rolls ou não, são predominantes na laminação de tiras a frio e atribui-se a esta predominância, principalmente, seu menor custo quando comparado ao aço rápido forjado.

Além do menor custo, outra explicação para a predominância do aço ao cromo forjado é encontrada quando se analisa a relação entre sua resistência ao desgaste com os níveis de produção comumente praticados. Em outras palavras, não há vantagem em se utilizar um material com maior resistência ao desgaste uma vez que não há grandes quantidades de uma única classe de aço para ser laminado.

A menor quantidade de uma única classe de aço para ser laminado pode ser atribuída aos desenvolvimentos dos aços para a indústria automobilística que indicam para o surgimento de novas classes de aços com maior resistência mecânica 0 que permitirá reduzir as dimensões dos componentes e consequentemente menor massa de aço laminado. Dessa forma, a resistência ao desgaste do cilindro torna-se de menor importância quando comparada a resistência dos cilindros aos esforços decorrentes da laminação desses aços de elevada resistência mecânica.

No sentido de acompanhar os novos requisitos do processo de laminação, a evolução de um material que foi desenvolvido há mais de 50 anos ainda é possível por meio de modificações de propriedades do cilindro que visam atender características específicas do laminador ao qual será destinado.

Desde o final do ano de 2011, a equipe técnica representante dos cilindros da marca Villares Rolls junto à equipe técnica da oficina de cilindros dos laminadores de tiras a frio da CSN/UPV realizaram em conjunto um detalhado estudo das causas de consumo dos cilindros de trabalho do laminador de tiras a frio destinado à indústria automobilística e com base nesse estudo aprimoraram as propriedades do cilindro de aço forjado com $5 \% \mathrm{Cr}$, por meio de tratamentos térmicos, para obter um maior desempenho.

Apresentam-se neste trabalho as melhorias de um produto já homologado na aplicação, o método utilizado nesta melhoria e os resultados obtidos dos cilindros em teste.

\section{MATERIAIS E MÉTODOS}

O estudo para o aumento de campanha dos cilindros de trabalho foi realizado no laminador de tiras a frio da CSN, unidade Presidente Vargas, que é destinado à laminação dos produtos para a indústria automobilística.

As etapas para a realização do estudo foram as seguintes:

i) determinação e classificação das causas de consumo dos cilindros. Nesta etapa foram analisados os milímetros removidos em cada corte por campanha e seus respectivos motivos de corte;

ii) descrição do mecanismo da principal causa de consumo. Uma vez identificado o motivo que resultou na maior quantidade de milímetros removidos, foi realizada uma análise não destrutiva na superfície do cilindro com o auxílio de um microscópio óptico portátil;

* Contribuição técnica ao $51^{\circ}$ Seminário de Laminação - Processos e Produtos Laminados e Revestidos, 28 a 31 de outubro de 2014, Foz do Iguaçu, PR, Brasil. 


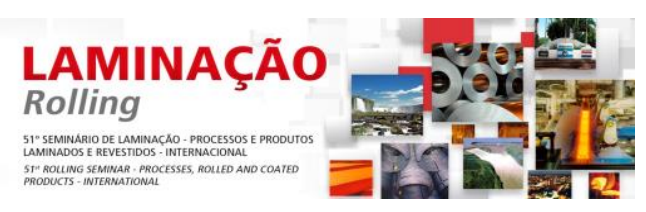

iii) associação do mecanismo da principal causa de consumo com propriedades mecânicas dos cilindros. Nesta etapa buscou-se correlacionar a principal causa de consumo com alguma propriedade mecânica do cilindro;

iv) fabricação e verificação dos cilindros fabricados para teste na redução do consumo. Nesta etapa foram fabricados cilindros para teste com alterações no seu processo de fabricação, especificamente no tratamento térmico, capaz de atender as propriedades mecânicas necessárias para reduzir o consumo dos cilindros.

Destaca-se ainda que, em todas as etapas acima descritas, foram fundamentalmente importantes as discussões presenciais realizadas entre os técnicos da CSN que gerenciam o consumo dos cilindros com os técnicos responsáveis pelo processo de fabricação dos cilindros da marca Villares Rolls.

\section{RESULTADOS}

\subsection{Determinação e Classificação das Causas de Consumo dos Cilindros}

A análise dos motivos de consumo dos cilindros de trabalho permitiu identificar que aproximadamente metade do consumo é devido aos cortes para eliminação de trincas decorrentes do processo de laminação.

A Figura 1 apresenta os principais motivos de consumo, observa-se que o consumo devido ao desgaste corresponde apenas a $1 / 4$ do consumo total.

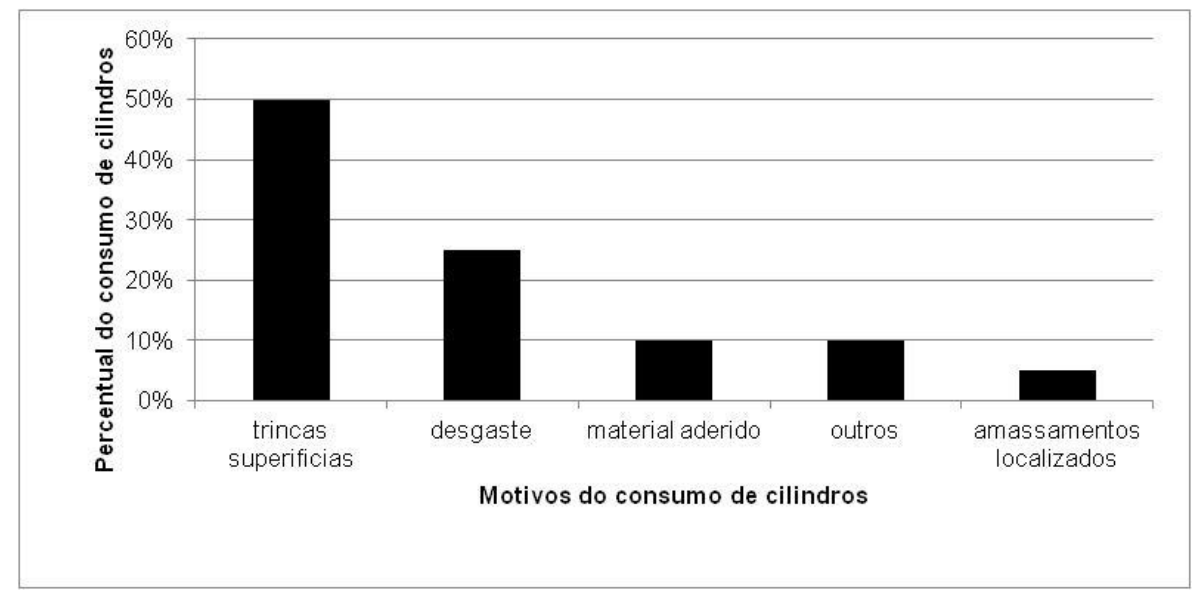

Figura 1: Distribuição do consumo dos cilindros por motivo.

Observa-se na Figura o percentual por cadeira das campanhas que tiveram cortes considerados normais, como aqueles devido ao desgaste, e aquelas campanhas na qual o corte foi superior ao esperado, a citar, principalmente, os cortes por trincas superficiais. As campanhas que resultaram no consumo devido ao desgaste correspondem a aproximadamente $75 \%$, isto permite concluir que as trincas superficiais, que representam metade do consumo, ocorreram em aproximadamente $25 \%$ das campanhas. 


\section{$\underset{\text { Rolling }}{\text { LAMINAÇO }}$}

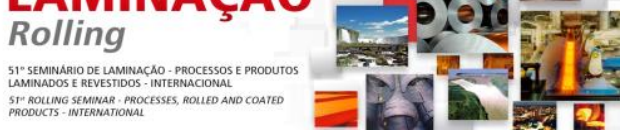

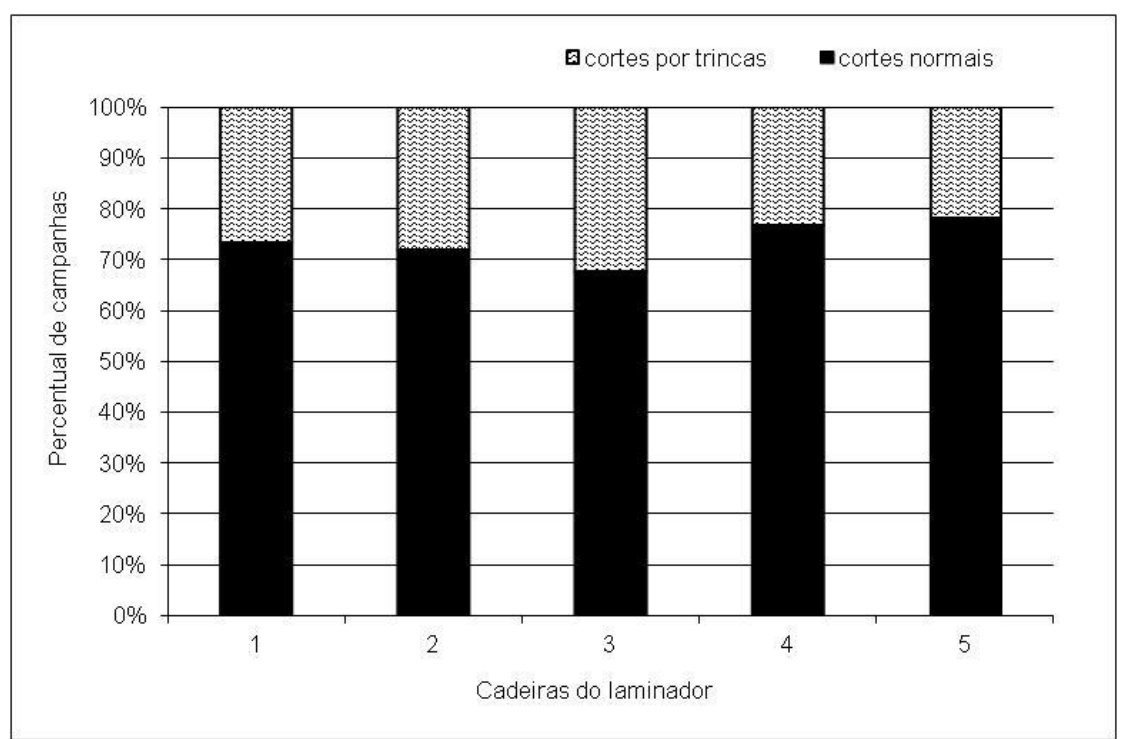

Figura 2: Percentual das campanhas por cadeira divida entre cortes normais e cortes por trincas.

\subsection{Descrição do Mecanismo da Principal Causa de Consumo}

Uma vez identificado que as trincas superficiais foram o principal motivo do consumo foi realizada a caracterização dessas trincas para identificar possíveis ações de redução do consumo. Nessa caracterização foi possível identificar que as trincas são paralelas entre si, perpendiculares ao sentido de laminação e associadas com adesão do material laminado ou alteração microestrutural do material do cilindro.

A Figura apresenta a caracterização realizada por microscopia óptica de um local do cilindro que apresentou trincas com material aderido da tira laminada. O mecanismo de formação dessas trincas é adesão seguida do deslocamento da tira. Este mecanismo de adesão seguido do deslocamento da tira pode ser observado na característica de onda de deformação do material aderido.

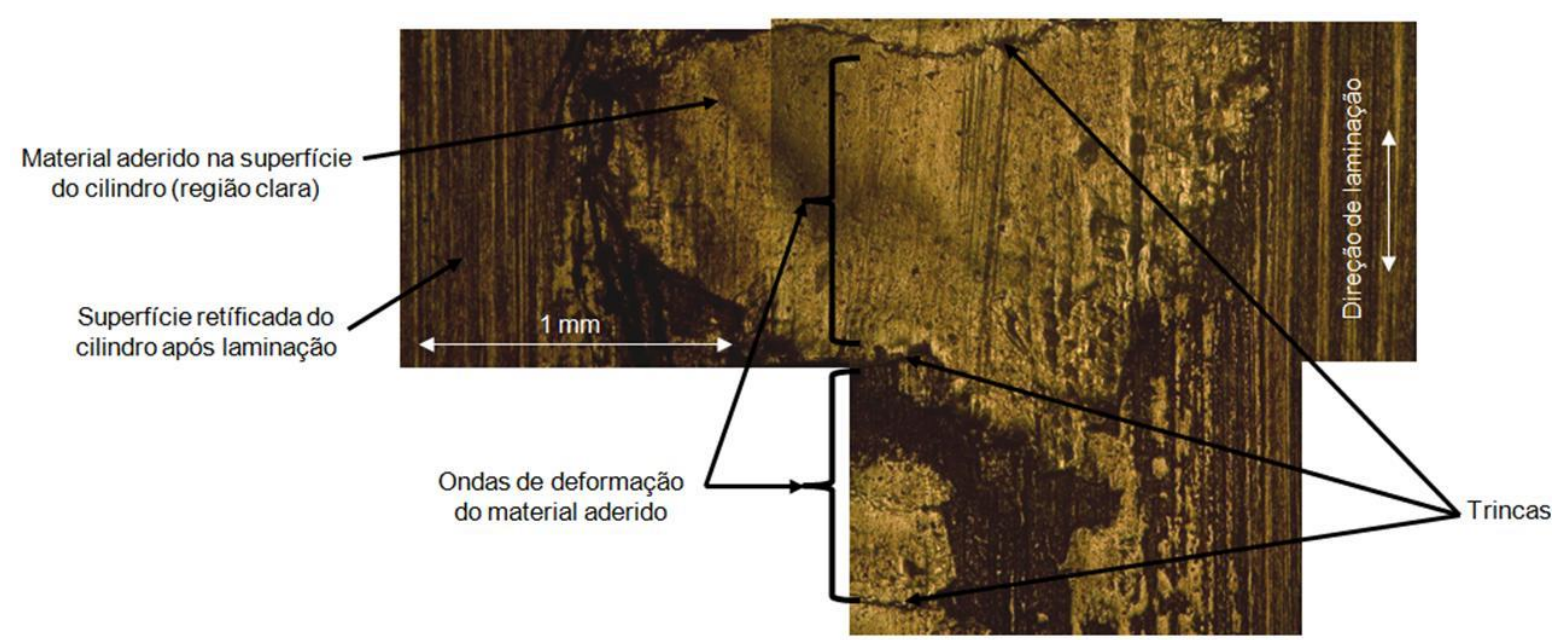

Figura 3: Caracterização das trincas com material da tira aderido na superfície do cilindro.

A Figura apresenta o segundo mecanismo de formação das trincas. Este mecanismo consiste do deslocamento deslizante com força localizada superior a força de laminação da tira e sem aderência do material laminado. A combinação da 


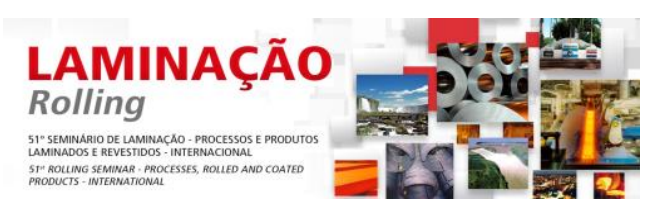

força localizada com o deslizamento do material resulta nas trincas e alteração microestrutural do material do cilindro. A alteração microestrutural pode ser associada com um aquecimento que ocorre durante este deslizamento.

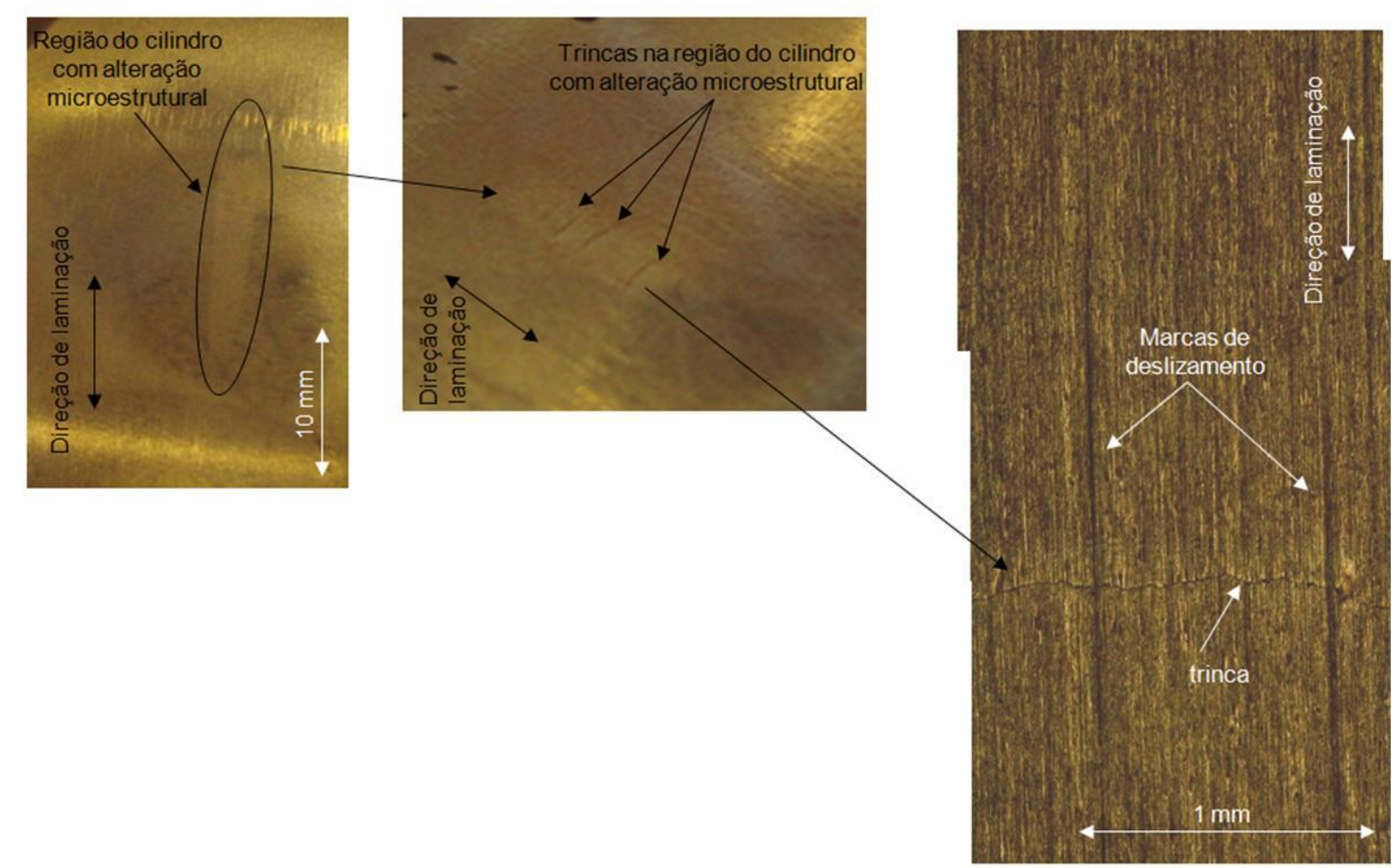

Figura 4: Caracterização das trincas devido ao deslizamento da tira e alteração da microestrutura do cilindro.

O mecanismo de formação das trincas foi apresentado na caracterização discutida anteriormente, porém não foi objetivo deste trabalho identificar as variáveis do processo de laminação associadas a este mecanismo, no presente trabalho focouse em propriedades do cilindro de laminação capaz de reduzir o consumo devido a essas trincas.

\subsection{Associação do Mecanismo da Principal Causa de Consumo com Propriedades Mecânicas dos Cilindros}

A relação entre os cortes por trincas com as propriedades mecânicas do material do cilindro pode ser discutida por meio do limite resistência a ruptura e tenacidade. Aumentar o limite de resistência à ruptura para evitar o surgimento da trinca resultará num material frágil, o que pode ter como conseqüência lascamentos do cilindro aumentando seu consumo. Por outro lado, um cilindro com maior tenacidade, ou menor dureza, não impede o surgimento das trincas, mas sim dificulta a propagação das trincas tornando-as menos profundas resultando em menores cortes para sua remoção e consequentemente reduzindo o consumo de cilindros.

A afirmação acima citada pode ser confirmada na Figura onde se apresenta o percentual dos cortes por trinca em função da dureza do cilindro ao longo de sua vida útil. Observa-se tendência de redução dos cortes por trinca com a redução da dureza. A tenacidade, por sua vez, possui relação inversa com a dureza. 


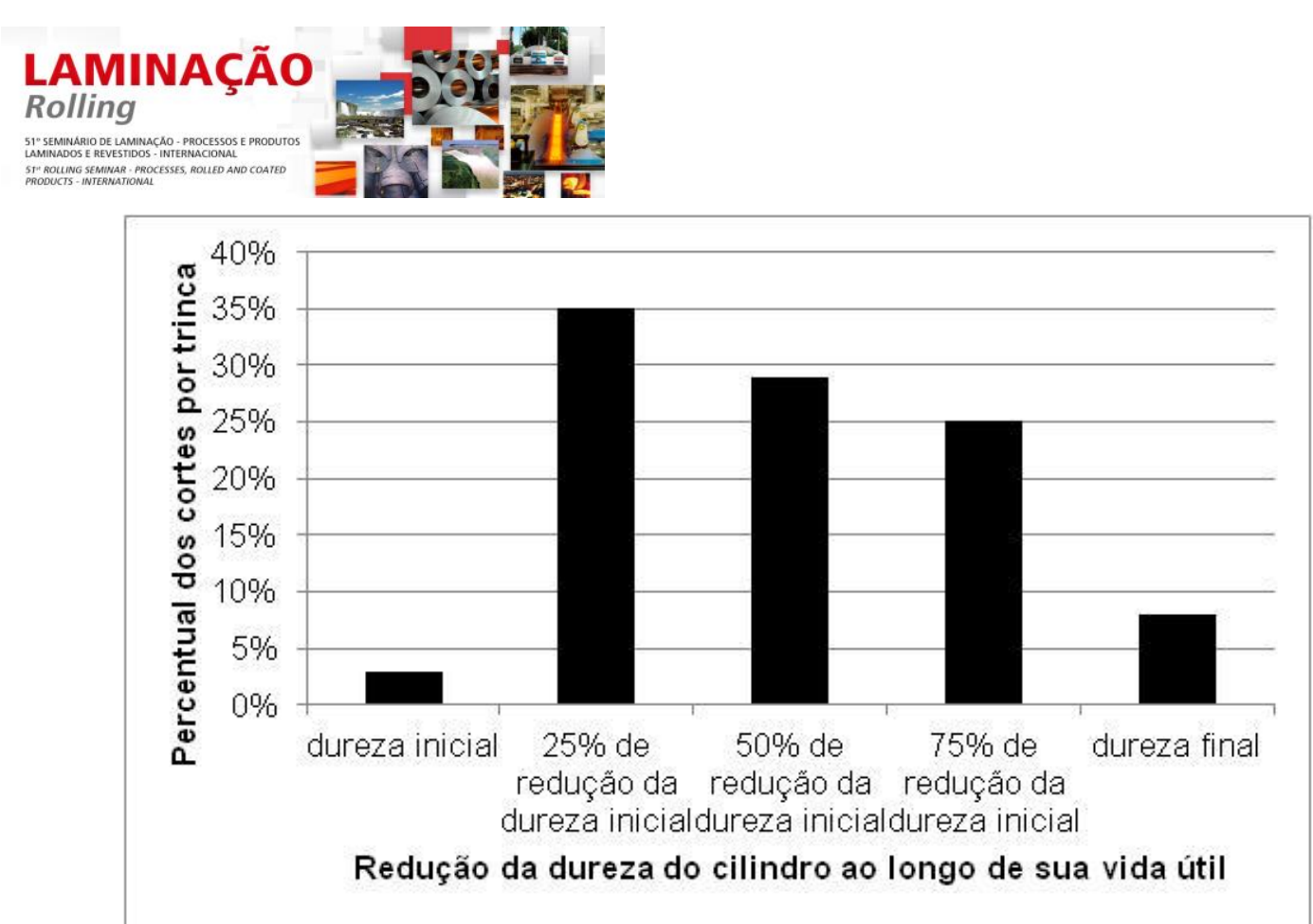

Figura 5: Relação dos cortes por trinca em função da queda de dureza do cilindro ao longo de sua vida útil.

O aumento da tenacidade do cilindro que é acompanhado pela redução de sua dureza pode aumentar o consumo por desgaste e amassamentos e cabe ao fornecedor desenvolver um cilindro que apresente dureza e tenacidade adequadas para as condições do processo de laminação. Dessa forma, apresenta-se a seguir o resultado dos testes em andamento para redução do consumo de cilindros por trincas.

\subsection{Fabricação e Verificação de Cilindros Fabricados para Teste de Redução do Consumo}

Os testes com cilindros com dureza e tenacidade adequadas para as condições do laminador em estudo iniciaram em 2012 com quatro cilindros, seguiram em 2013 com mais doze cilindros e em 2014 foram fornecidos mais 20 cilindros para teste. 0 crescente número de cilindros permitiu obter um aumento significativo na utilização desses cilindros em teste.

O número de utilizações é muito importante, pois conforme apresentado anteriormente os cortes por trinca ocorrem em apenas $25 \%$ das campanhas. O reduzido número de utilizações pode coincidir com campanhas normais ou campanhas onde ocorreram trincas.

Observa-se na Figura, que apresenta a diferença de desempenho dos cilindros em teste na cadeira 5 com relação aos demais cilindros utilizados nesta cadeira, a grande diferença no resultado obtido nos anos de 2012 e 2013. Atribui-se a esta diferença o reduzido número de utilizações nestes anos, que foi de $1 \%$ e $10 \%$, respectivamente.

Ainda na Figura observa-se que com o aumento do número de cilindros em teste, o percentual de utilizações atingiu $43 \%$ do total de utilizações da cadeira 5 no ano de 2014, o aumento do desempenho neste período foi de $22 \%$.

* Contribuição técnica ao $51^{\circ}$ Seminário de Laminação - Processos e Produtos Laminados e Revestidos, 28 a 31 de outubro de 2014, Foz do Iguaçu, PR, Brasil. 


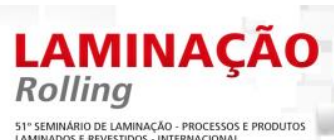

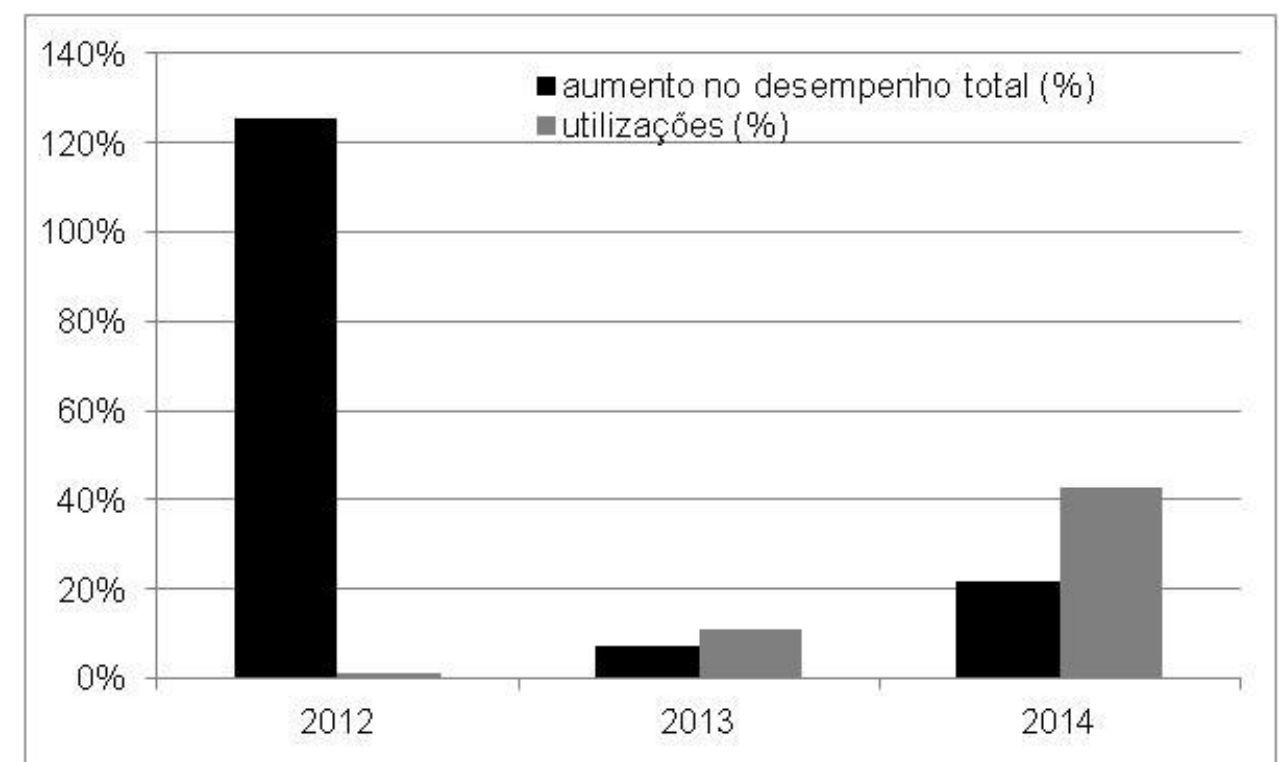

Figura 6: Desempenho e percentual de utilizações dos cilindros em teste na cadeira 5.

Os cilindros em teste já foram utilizados em todas as cinco cadeiras, porém com número de utilizações ainda pouco significativo. Na cadeira 1, por exemplo, que é atualmente a segunda cadeira com o maior número de utilizações dos cilindros em teste, $22 \%$ do total de utilizações, o desempenho dos cilindros em testes é duas vezes maior quando comparado ao desempenho dos demais cilindros nesta cadeira. Novos fornecimentos de cilindros para teste estão programados para o ano de 2014 e espera-se até o final deste ano obter $50 \%$ do total das utilizações nas cadeiras 1 e 5 com desempenho médio superior a $22 \%$.

\section{CONCLUSÃO}

O estudo para o aumento do desempenho dos cilindros de trabalho para laminação de tiras a frio permitiu concluir que:

i) o principal motivo de consumo é devido aos cortes para a eliminação de trincas;

ii) as trincas são o resultado de ondas de deformação do material laminado aderido a superfície do cilindro e também do deslizamento localizado do material laminado com o cilindro;

iii) os testes dos cilindros com maior tenacidade permitiram obter até momento, aumento de desempenho de aproximadamente $22 \%$;

iv) o trabalho em conjunto entre fornecedor e usuário permitiu desenvolver melhorias de desempenho mesmo num produto utilizado por mais de 50 anos nesta aplicação. 